\title{
EDITORIAL
}

\section{BRADYPEDIA: IS GAIT SPEED READY FOR CLINICAL USE?}

\section{S. STUDENSKI}

Professor, University of Pittsburgh, Staff Physician, Pittsburgh Veterans Affairs Medical Center, Mailing address: 3471 Fifth Ave Suite 500 Pittsburgh Pa 15213 , Email: sas33@pitt.edu

Mobility, or locomotion, could be considered a distinguishing feature of the entire animal kingdom. It is central to the ability to obtain food, escape danger and survive. Interestingly, across virtually all animal species, aging is associated with generalized slowing of movement (1-3). In humans, the capacity to move underlies many basic and community functions necessary for independence. For these reasons, a simple indicator of mobility has the potential to serve as a core indicator of health and function in aging and disease. In the current issue of JNHA, a Task Force of the International Academy on Nutrition and Aging has made an invaluable contribution to the field of mobility and aging by summarizing the literature on the predictive capacity of usual gait speed in older persons (4). Using rigorous methods to identify sources of evidence, they combined information from diverse aging populations and used high priority outcomes to assess potential validity. Gait speed was a powerful predictor of survival, disability, hospitalization or institutionalization, dementia and falls. The Task Force also considered practical issues related to feasibility in clinical settings in order to generate initial guidelines for use in practice and clinical research.

Why would a simple measure like gait speed predict such a wide array of outcomes? Since slowing appears to be a universal biological phenomenon reflecting the vitality of animal life, it is likely to reflect the integrated performance of numerous organ systems $(5,6)$. Walking requires body support, timing and power. It places demands on the brain, spinal cord, peripheral nerves, muscles and joints, heart and lungs, and perhaps, through the need for oxygen carrying capacity, the blood. Thus when organ systems are not working properly, gait speed slows. Sometimes the dysfunction of organ systems is recognized as disease, such as congestive heart failure, arthritis or stroke. Other times, the organ system dysfunction is either "subclinical" or hard to characterize as a diagnosis, and is attributed to "old age". Interestingly, since gait speed reflects the simultaneous working of so many organ systems, it may help estimate the overall burden of disease, both diagnosed and unrecognized, and this reflection of total burden may be the mechanism by which gait speed predicts multiple outcomes. Walking speed might be used clinically like other simple indicators of the well being of the organism, as a "vital sign". Like body temperature, blood pressure or respiratory rate, gait speed may be a nonspecific indicator with normal and abnormal ranges. Abnormalities might have numerous potential causes but persistently abnormal vital signs are serious prognostic

Received September 14, 2009

Accepted for publication September 24, 2009 indicators of poor health. Walking speed also reflects energy expenditure and can be related to the energy demands of daily life. The Compendium of Physical Activities provides information on the energy required to walk at many different speeds (7). For example, walking at about 1.5 miles per hour (equivalent to $2.5 \mathrm{~km} /$ hour and a gait speed of about .67 meters per second requires about $7 \mathrm{ml} / \mathrm{kg} / \mathrm{min}$ of oxygen or 2 METS. Walking at 2.5 miles per hour $(4.2 \mathrm{~km} /$ hour or about $1.1 \mathrm{~m} / \mathrm{sec})$ requires about 3 METS. Energy requirements for self care activities like bathing or dressing are about 2 METS and for community activities like carrying groceries or light yard work are about 3 METS. Thus, persons who walk less than .67 meters per second may be most likely to be limited in the energy needed for self care and persons who walk over 1.1 meters per second may be expected to have the energy capacity to perform household activities. Since functional capacity for self care and household maintenance are important for independence in late life, gait speed can reflect the functional capacity for independent living and helps predict disability.

The Task Force has demonstrated the potential for gait speed to be used as a screen or predictor of future adverse health events, but the clinical utility of gait speed may have several other applications as well. First, gait speed might help quickly identify individuals with current disability. The field of geriatrics has long sought to promote the value of integrating biomedical care with evaluation and management of disability. To date, it has been difficult to get providers to adopt functional screening, perhaps because functional screening takes too long, or because it is based on self-report rather than some "objective" measure. Since slow gait speeds (eg less than 0.6 meters/second) are likely to be associated with current disability, perhaps providers could identify very slow walkers as persons in need of further evaluation and management of disability. Second, providers could approach abnormal gait speed as a diagnostic test to identify a clinical problem to be evaluated and treated. Since the systems that contribute to the ability to walk can be enumerated, it is possible to define a differential diagnosis of slow walking speed that can be used to identify and treat abnormalities $(5,6)$. Third, repeated measures of gait speed could be used clinically and in clinical trials as a way to assess change over time (8-10). Thus an improvement in gait speed might be a good indicator of the effectiveness of a treatment or rehabilitation program and further slowing might indicate a new or worsening medical problem. 
If gait speed has potential clinical utility, what else must be done to provide sufficient evidence for it to be adopted in routine care? There are several necessary next steps. First, there must be continued efforts to clarify and standardize measures $(11,12)$. As noted in the Task Force report, there are variations in technique, including starting conditions and length of the walk. Additionally, some measures incorporate other tasks or instructions. For example, the Timed Up and Go includes a chair rise and turn (13). Some investigators prefer to ask individuals to walk as fast as possible, rather than at usual pace (14). It is not yet known whether or how these modifications provide additional value to usual walking speed. Perhaps most challenging is whether it is possible to align the information gained from longer walks with the information from usual gait speed in short walks. Longer walks could be preferred in some cases because they might reflect endurance better than short walks (15). Interestingly, the six minute walk, the most widely used long walk, is becoming widely accepted by health care providers who focus on congestive heart failure, chronic obstructive pulmonary disease and other conditions (16-19). Some investigators have suggested that another long walk, the 400 meter walk, is especially helpful in distinguishing among higher levels of fitness and function (20). It is not yet known how much additional information is provided by longer over shorter walks, but this question is easily amenable to investigation. Interestingly, a recommended cutoff for the six minute walk is 350 meters, which is almost identical to a gait speed of around 1.0 meters per second, a cutoff for normal gait speed considered by the task force and others $(21,22)$. It may be possible to detect individuals who perform so slowly on a short walk that they are clearly identified and don't need to perform a longer task. It is also possible that endurance is incorporated into usual walking speed since some authors suggest that individuals self select their personal optimal walking speed which is adjusted for their aerobic capacity and their energy cost of walking $(23,24)$. An approach to aligning shorter and longer walks would help engage the many medical specialists who are already using longer walks in patient care.

Future development of gait speed for clinical use will also require using clinical rather than epidemiological metrics. For example, while odds ratios and relative risks are helpful for estimating population risk, they are not as useful in patient care. More helpful for patient care are estimates of absolute risk, positive and negative predictive value and likelihood ratio (25), which can be applied to the individual case. Perhaps gait speeds could be defined in terms of diagnostic testing, where there is more than one clinically relevant level, reflecting such states as seriously abnormal, mildly abnormal, normal/acceptable and superior. Based on the data provided by the Task Force, such levels might be defined as follows; less than 0.6 meters per second is seriously abnormal, 0.6 to 1.0 is mildly abnormal, 1.0 to 1.4 is normal and 1.4 or higher is superior.

While the Task Force provides useful summaries of available data, the information is still somewhat fragmented and individual studies are diverse. Further work could be done to develop more precise estimates and examine potential subgroup effects by pooling data across studies to perform formal meta- analyses using very large sample sizes. It is possible that clinical applications of gait speed would benefit from estimates that are specific to subgroups based on gender and age or that consider other factors such as ethnicity, weight, height or classes of medical condition. It might also be useful to compare clinical utility of gait speed to other widely used general indicators such as blood pressure or body mass index.

Finally, if slowing is a serious health problem of aging, and gait speed helps detect it, then in order to be incorporated into clinical practice and health care planning, the problem needs a name. As a diagnostic term, consider bradypedia, a simple latin derivative that parallels other terms such as hypertension or tachycardia. The seriously abnormal condition that requires attention to evaluation and management would be "bradypedia". The mildly abnormal condition that is the focus of preventive efforts against future adverse events might be "subclinical or mild bradypedia".

Slowing down has been recognized as an indicator of failing health and vulnerable old age throughout history. Perhaps it is time to recognize this universal phenomenon within health care.

"my legs do not carry me

Which once were swift to dance, like young fawns..

But what can I do?

Be ageless?"

-Greek poet 6th Century BC

\section{References}

1. Bolanowski MA, Russell RL, Jacobson LA 1981 Quantitative measures of aging in the nematode Caenorhabditis elegans. I. Population and longitudinal studies of two behavioral parameters. Mech Ageing Dev 15(3):279-95.

2. McAuley JD, Miller JP, Pang KC 2004 Age-related changes in the spontaneous motor rhythms of the senescence-accelerated mouse (SAMP8). Exp Aging Res 30(1):113-27.

3. Zhang Z, Andersen A, Smith C, Grondin R, Gerhardt G, Gash D 2000 Motor slowing and parkinsonian signs in aging rhesus monkeys mirror human aging. J Gerontol A Biol Sci Med Sci 55(10):B473-80.

4. Abellan van Kan G, Rolland, Y., Andrieu, S., Anthony, P. Bauer, J., Beauchet, O., Bonnefoy, M., Cesari, M., Donini, L.M., Gillette-Guyonnet, S., Inzitari, M., Jurk, I., Nourhashemi, F., Offord-Cavin, E., Onder, G.,, Ritz P, Salva, A., Visser, M., Vellas, B. 2009 Gait Speed at usual pace as a predictor of adverse outcomes in community-dwelling older people. J Nutr Health Aging. 2009; 13(10):881-889

5. Brach J, Rosano, C., Studenski, S. 2009 Mobility. In: Halter J (ed.) Textbook of Geriatrics and Gerontology. McGraw Hill.

6. Ferrucci L, Bandinelli S, Benvenuti E, Di Iorio A, Macchi C, Harris TB, Guralnik JM 2000 Subsystems contributing to the decline in ability to walk: bridging the gap between epidemiology and geriatric practice in the InCHIANTI study. J Am Geriat Soc 48(12): 1618-25.

7. Ainsworth BE, Haskell WL, Whitt MC, Irwin ML, Swartz AM, Strath SJ, O'Brien WL, Bassett DR, Jr., Schmitz KH, Emplaincourt PO, Jacobs DR, Jr., Leon AS 2000 Compendium of physical activities: an update of activity codes and MET intensities. Med Sci Sports Exerc 32(9 Suppl):S498-504.

8. Hardy SE, Perera S, Roumani YF, Chandler JM, Studenski SA 2007 Improvement in usual gait speed predicts better survival in older adults. J Am Geriatr Soc 55(11):1727-34

9. Perera S, Mody SH, Woodman RC, Studenski SA 2006 Meaningful change and responsiveness in common physical performance measures in older adults. J Am Geriatr Soc 54(5):743-9. 


\section{BRADYPEDIA: IS GAIT SPEED READY FOR CLINICAL USE?}

10. Perera S, Studenski S, Chandler JM, Guralnik JM 2005 Magnitude and patterns of decline in health and function in 1 year affect subsequent 5-year survival. J Geronto A Biol Sci Med Sci 60(7):894-900.

11. Graham JE, Ostir GV, Fisher SR, Ottenbacher KJ 2008 Assessing walking speed in clinical research: a systematic review. J Eval Clin Pract 14(4):552-62.

12. Graham JE, Ostir GV, Kuo YF, Fisher SR, Ottenbacher KJ 2008 Relationship between test methodology and mean velocity in timed walk tests: a review. Arch Phys Med Rehabil 89(5):865-72.

13. Podsiadlo D, Richardson S 1991 The timed "Up \& Go": a test of basic functional mobility for frail elderly persons. J Am Geriatr Soc 39(2):142-8.

14. Cesari M, Pahor M, Marzetti E, Zamboni V, Colloca G, Tosato M, Patel KV, Tovar JJ, Markides K 2009 Self-assessed health status, walking speed and mortality in older Mexican-Americans. Gerontology 55(2):194-201.

15. Simonsick EM, Fan E, Fleg JL 2006 Estimating cardiorespiratory fitness in wellfunctioning older adults: treadmill validation of the long distance corridor walk. J Am Geriatr Soc 54(1):127-32.

16. Bittner V, Weiner DH, Yusuf S, Rogers WJ, McIntyre KM, Bangdiwala SI, Kronenberg MW, Kostis JB, Kohn RM, Guillotte M, et al. 1993 Prediction of mortality and morbidity with a 6-minute walk test in patients with left ventricular dysfunction. SOLVD Investigators. JAMA 270(14):1702-7.

17. Enright PL, McBurnie MA, Bittner V, Tracy RP, McNamara R, Arnold A, Newman AB 2003 The 6-min walk test: a quick measure of functional status in elderly adults. Chest 123(2):387-98.

18. Sciurba F, Criner GJ, Lee SM, Mohsenifar Z, Shade D, Slivka W, Wise RA 2003 Six-minute walk distance in chronic obstructive pulmonary disease: reproducibility and effect of walking course layout and length. Am J Respir Crit Care Med 167(11):1522-7.
19. Solway S, Brooks D, Lacasse Y, Thomas S 2001 A qualitative systematic overview of the measurement properties of functional walk tests used in the cardiorespiratory domain. Chest 119(1):256-70.

20. Newman AB, Simonsick EM, Naydeck BL, Boudreau RM, Kritchevsky SB, Nevitt MC, Pahor M, Satterfield S, Brach JS, Studenski SA, Harris TB 2006 Association of long-distance corridor walk performance with mortality, cardiovascular disease, mobility limitation, and disability. JAMA 295(17):2018-26.

21. Rasekaba T, Lee AL, Naughton MT, Williams TJ, Holland AE 2009 The six-minute walk test: a useful metric for the cardiopulmonary patient. Intern Med J 39(8):495 501

22. Cesari M, Kritchevsky SB, Penninx BW, Nicklas BJ, Simonsick EM, Newman AB, Tylavsky FA, Brach JS, Satterfield S, Bauer DC, Visser M, Rubin SM, Harris TB, Pahor M 2005 Prognostic value of usual gait speed in well-functioning older people-results from the Health, Aging and Body Composition Study. J Am Geriatr Soc 53(10): $1675-80$

23. Malatesta D, Simar D, Dauvilliers Y, Candau R, Ben Saad H, Prefaut C, Caillaud C 2004 Aerobic determinants of the decline in preferred walking speed in healthy, active 65- and 80-year-olds. Pflugers Arch 447(6):915-21.

24. Malatesta D, Simar D, Dauvilliers Y, Candau R, Borrani F, Prefaut C, Caillaud C 2003 Energy cost of walking and gait instability in healthy 65- and 80-yr-olds. J App Physiol 95(6):2248-56.

25. Jaeschke R, Guyatt GH, Sackett DL 1994 Users' guides to the medical literature. III. How to use an article about a diagnostic test. B. What are the results and will they help me in caring for my patients? The Evidence-Based Medicine Working Group JAMA 271(9):703-7. 